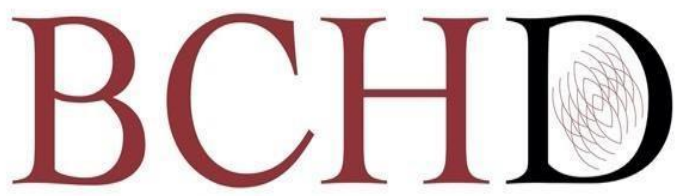

Bioactive Compounds in Health and Disease

\title{
Saffron and depression
}

\section{Sedigheh Asgary ${ }^{1 *}$, Zeinab Yazdiniapour ${ }^{2}$}

${ }^{1}$ Isfahan Cardiovascular Research Center, Cardiovascular Research Institute, Isfahan University of Medical Sciences, Isfahan, 81746-73461, Iran; ${ }^{2}$ Faculty of Pharmacy, Isfahan University of Medical Sciences, Isfahan, 81746-73461, Iran

*Corresponding author: Sedigheh Asgary, Doctor of Pharmacy, PhD, Professor, Isfahan Cardiovascular Research Center, Cardiovascular Research Institute, Isfahan University of Medical Sciences, Isfahan, 81746-73461, Iran

Submission Date: May 9 ${ }^{\text {th }}, 2021$; Acceptance Date: May 24 ${ }^{\text {th }}, 2021$; Publication Date: May $27^{\text {th }}, 2021$

Please cite this article as: Asgary S., Yazdiniapour Z. Saffron and depression. Bioactive Compounds in Health and Disease 2021. 4(5): 90-92. DOI: 10.31989/bchd.v4i5.808

\section{EDITORIAL}

Throughout the centuries, people have used the dried stigma of Crocus sativus that is known as "saffron" for medicinal and nutritional purposes [1]. Studies have shown that not only is saffron well worth the money, but also, its bioactive compounds (including crocin, precrocin, and safranal that are responsible for color, taste and fragrance respectively) play a crucial role in the central nervous system to positively affect conditions such as anxiety and depression [2-5]. Saffron compounds are also neuroprotective and anxiolytic and can benefit learning and memory impairments [6].

Nowadays, people who experience a low standard of living suffer from depression which is the most widespread psychiatric malady around the world. The most popular antidepressants that are prescribed by physicians are tricyclics antidepressants
(TCAs), selective serotonin reuptake inhibitors (SSRIs), and selective serotonin noradrenaline reuptake inhibitors (SSNRIs). Their primary mechanism works by enhancing the accessibility of serotonin, a special neurotransmitter [7]. Epidemiological evidence implies that there is a close relationship between diet quality and mental health among demographic and age groups. Therefore, dietary habits that contain saffron extract has become an inspiring and aspirational part of subsequent investigations [8]. Identification agents and famous medications such as second-generation antipsychotics, levothyroxine, and other drugs are substantial ways for increasing the capability of the currently available antidepressants (ADs) as nutraceuticals and over the counter (OTC) drugs in modern psychopharmacology [9]. To clarify this point, 
in many clinical trials, the therapeutic effect of saffron, with its essential components was equal to antidepressants, (fluoxetine, imipramine, and citalopram) [10-12]. Moreover, information from other interventional studies indicated that saffron is even more impressive compared to placebo and synthetic antidepressant drugs, especially when accompanied by antioxidants, anti-inflammatory, and serotonergic compounds etc. That means saffron could be an appropriate alternative to remedies for mild to moderate depression, with fewer reported side effects, compared to standard drugs [11, 13-14]. As mentioned earlier, both saffron and sertraline have potential in treatments for depression, but saffron appears more powerful in adults, especially those with premenstrual syndrome, those in post- menopause, and those who experience hot flashes. Usually, these individuals would consume fluoxetine and Non-Steroidal Anti-Inflammatory Drugs (NSAIDs) [15-17].

It is frequently asserted that $C$. sativus and its constituents help to treat depression through multiple mechanisms of raising glutamate and dopamine levels in the brain in a dose-dependent manner and also by interacting with the opioid system to alleviate withdrawal syndrome [18-20].

Health authorities need to increase public awareness about this valuable herbal as an adjuvant supplement for the pharmaceutical industry and as a golden and fragrant spice in households which can fight off moderate depression in every person and is recommended for stress-induced obesity [21-22].

\section{REFERENCES}

1. Siddiqui MJ, Saleh MSM, Basharuddin SNBB, Zamri SHB, MHBM Najib, Ibrahim MZBC, Noor NABM, Mazha HNB, Hassan NM, Khatib A: Saffron (Crocus sativus L.): As an Antidepressant. J Pharm Bioallied Sci 2018 , 8;10(4):173-180.

2. Salwee $Y$, Nehvi FA: Saffron as a valuable spice: a comprehensive review. African J Agric Res. 2013, 8(3):234-242.

3. Abu-Izneid T, Rauf A, Khalil AA, Olatunde A, Khalid A Alhumaydhi FA, Aljohani ASM, Uddin MS, Heydari M, Khayrullin M, Shariati MA, Aremu AO, Alafnan AA, Rengasamy KRR: Nutritional and health beneficial properties of saffron (Crocus sativus L): a comprehensive review. Critical Reviews in Food Science and Nutrition 2020, 17:1-24.

4. Pitsikas $\mathrm{N}$ : Crocus sativus $\mathrm{L}$. extracts and its constituents crocins and safranal; potential candidates for schizophrenia treatment. Molecules 2021, 26(5):112

5. Rios J: Medicinal plants in the treatment of depression: Evidence from preclinical studies. Planta Medica 2021, 6.

6. Srivastava R, Ahmed H, Dixit RK, Dharamveer, Saraf SA: Crocus sativus L.: A comprehensive review. Pharmacogn Rev 2010, 4(8):200-208.

7. Bian Y, Zhao C, Lee SM: Neuroprotective Potency of Saffron Against Neuropsychiatric Diseases,
Neurodegenerative Diseases, and Other Brain Disorders: From Bench to Bedside 2020, 11: 1-13.

8. Marx W, Hoare E, Jacka F: Diet and depression: from epidemiology to novel therapeutics. Neurobiology of Depression 2019: 285-292.

9. Dome P, Tombor L, Lazary J, Gonda X, Rihmer Z: Natural health products, dietary minerals and overthe-counter medications as add-on therapies to antidepressants in the treatment of major depressive disorder: a review. Brain Res Bull 2019, 146:51-78.

10. Singletary K: Saffron: Potential health benefits. Nutrition Today 2021, 55(6):294-303.

11. Shafiee M, Arekhi S, Omranzadeh A, Sahebkar A: Saffron in the treatment of depression, anxiety and other mental disorders: Current evidence and potential mechanisms of action. J Affect Disord 2018, 227:330-337.

12. Clinical Applications of Saffron (Crocus sativus) and its Constituents : A Review. 2015, 287-295.

13. Dai L, Chen L, Wang W: Safety and Efficacy of Saffron (Crocus sativus L.) for Treating Mild to Moderate Depression: A Systematic Review and Meta-analysis. J Nerv Ment Dis 2020, 208(4):269-276.

14. Lopresti AL, Drummond PD: Saffron (Crocus sativus ) for depression: a systematic review of clinical studies and examination of underlying antidepressant mechanisms of action 2014, 517-527. 
15. Ahmadpanah M, Ramezanshams F, Ghaleiha A, Akhondzadeh S, Sadeghi Bahmani D, Brand S: Crocus Sativus L. (saffron) versus sertraline on symptoms of depression among older people with major depressive disorders-a double-blind, randomized intervention study. Psychiatry Res 2019, 282.

16. Nemat-Shahi M, Asadi A, Nemat-Shahi M, Soroosh D, Mozari S, Bahrami-Taghanaki $\mathrm{H}$ et al.: Comparison of saffron versus fluoxetine in treatment of women with premenstrual syndrome: A randomized clinical trial study. Indian J Forensic Med Toxicol. 2020, 14(2):1760-1765.

17. Kashani L, Esalatmanesh S, Eftekhari F, Salimi S, Foroughifar T, Etesam F, Safiaghdam H, Moazen-Zadeh E, Akhondzadeh S: Efficacy of Crocus sativus (saffron) in treatment of major depressive disorder associated with post-menopausal hot flashes: a double-blind, randomized, placebo-controlled trial. Arch Gynecol Obstet 2018, 297(3):717-724.

18. Khazdair MR, Boskabady MH, Hosseini M, Rezaee R, M Tsatsakis A: The effects of Crocus sativus (saffron) and its constituents on nervous system: A review. Avicenna J phytomedicine 2015, 5(5):376-391.

19. Vahdati Hassani F, Naseri V, Razavi BM, Mehri S, Abnous K, Hosseinzadeh $\mathrm{H}$ : Antidepressant effects of crocin and its effects on transcript and protein levels of CREB, BDNF, and VGF in rat hippocampus. Daru 2014, 22(1):1-9.

20. Kiashemshaki B, Safakhah H-A, Ghanbari A, Khaleghian A, Miladi-Gorji H: Saffron (Crocus sativus L.) stigma reduces symptoms of morphine-induced dependence and spontaneous withdrawal in rats. Am J Drug Alcohol Abuse 2021, 47(2):170-181.

21. Akhondzadeh S, Mostafavi S-A, Keshavarz SA, Mohammadi MR, Hosseini S, Eshraghian MR: A placebo controlled randomized clinical trial of Crocus sativus L. (saffron) on depression and food craving among overweight women with mild to moderate depression. J Clin Pharm Ther 2020, 45(1):134-143.

22. Gout B, Bourges C, Paineau-Dubreuil S: Satiereal, a Crocus sativus $\mathrm{L}$ extract, reduces snacking and increases satiety in a randomized placebo-controlled study of mildly overweight, healthy women. Nutr Res 2010, 30(5):305-313. 